\title{
Study of Socio- Demographic Profile of Deaths due to Burns in Autopsies Conducted at Gandhi Medical College, Bhopal
}

\author{
Rajendra Kumar Mourya ${ }^{1}$, Priyamvada Kurveti Verma ${ }^{2}$, Dheeraj Singh Verma ${ }^{3}$ \\ ${ }^{1}$ Assistant Professor, Department of Forensic Medicine and Toxicology, Government Medical College, Shivpuri, \\ Madhya Pradesh, India, ${ }^{1}$ Ex-Resident, ${ }^{2}$ Associate Professor, ${ }^{3}$ Demonstrator; Department of Forensic Medicine \\ and Toxicology, Gandhi Medical College, Bhopal, Madhya Pradesh, India
}

\begin{abstract}
In India, incidence of burn injuries is quite high due to widespread illiteracy, old customs like dowry and use of kerosene for lighting and cooking; poverty, overcrowding and unemployment, other social \& emotional factors, lack of safety measures at industrial setup \& lack of adequate healthcare services. Although, mortality in cases of burns has been reduced considerably by modern advance healthcare services, yet death due to burns is not an uncommon event.

The study was carried out with the aim to study the various demographic parameters related to deaths due to burns such as age, sex, occupation, socio-economic status, marital status, locality and source of fire.

It was a 1.6 years prospective study of cases of burns autopsied at the mortuary of Gandhi medical college, Bhopal. The relevant information was obtained from inquest papers, history provided by relatives of the deceased and postmortem examination.

On data analysis, it was found that incidence of burns was found to be higher higher in females $(55.0 \%)$ as compared to males (45.0\%). young adults between the age group of 21-30 years have been the major victims of burns $(41.00 \%)$. In both sexes, majority of the burn cases were married (74\%). Most of the burn cases belonged to middle class, were housewives (51\%). and from rural areas (75\%). Hence, steps need be taken by Govt., NGOs and medical professionals to reduce the mortality due to burns.
\end{abstract}

Keywords: burns, demographic, incidence, post mortem.

\section{Introduction}

Invention of fire was the one of the greatest achievement of the human civilization. It is a double edged sword for man. Burn is an injury produced by application of dry/moist heat such as fire flame, boiling liquids, corrosive chemicals, radiant heat or some heated substances like metal, glass to the body. Local injury to the body by heat may result from dry heat, application

\section{Corresponding Author:}

\section{Dr. Priyamvada Kurveti Verma,}

Associate Professor, Department of Forensic Medicine and Toxicology, Gandhi Medical College, Bhopal, Madhya Pradesh, India, Phone- 7879793466, 8839367975, Email- rayan.priya@gmail.com of hot bodies, licking by flames result in simple burns, moist heat leads to scald, corrosive chemicals result in corrosive burns. Electric spark, discharges, flashes \& lightning leads to Electric burns. ${ }^{18}$

Every year more than 02 million people sustain burns in India. ${ }^{4}$ As per WHO, women in the South East Asia region have highest rate of burns, accounting for $27 \%$ of global burn deaths and nearly $70 \%$ of burn deaths in the region. ${ }^{19}$

In India, incidence of burns is quite high due to widespread illiteracy, old customs like dowry, and use of kerosene for lighting, cooking, poverty; overcrowding and unemployment, other social \& emotional factors, lack of safety measures at industrial setup \& lack of 
adequate healthcare services. Although, mortality in cases of burns has been reduced considerably by advanced healthcare services, yet death due to burns is not an uncommon event.

This study was conducted to study the various demographic parameters related to deaths due to burns such as age, sex, occupation, socio-economic status, marital status, locality and source of fire.

\section{Material and Methods}

Present study was carried out in the Department of Forensic Medicine and Toxicology, at Gandhi Medical College\& associated Hamidia Hospital, Bhopal for a period of 1.6 years.
All the burn cases either admitted or directly brought dead to the Hamidia Hospital Bhopal, cases with proper hospital records and cases of spot death due to burns were included. Out of those, 100 cases were selected for the study, by simple random sampling.

The detailed information pertaining to case such as age, sex, residence, marital status, education, occupation, date $\&$ time of the incidence, date $\&$ time of death, place of burns \& alleged cause of burns, source of catching fire etc. were collected from accompanying police personal, relatives, friends, neighbors or any other available person present at the time of incidence, by a questionnaire. Thorough $\&$ complete post-mortem examination was done in each case and autopsy reports analyzed with the relevant laboratory reports.

\section{Results and Discussion}

On analyzing the data, following results were obtained:

\section{Sex wise distribution of cases}

Table-1: depicts Sex wise distribution of burn deaths $(n=100)$

\begin{tabular}{|c|c|c|}
\hline Sex & No. of cases & Percentage \\
\hline Male & 37 & $37.0 \%$ \\
\hline Female & 63 & $63.0 \%$ \\
\hline Total & 100 & $100 \%$ \\
\hline
\end{tabular}

Out of the 100 cases, included in the study, there were 37 males $(37.0 \%)$ and 63 females $(63.0 \%)$. Thus, females outnumbered males and male female ratio was 1:1.702. This is similar to the findings of Mangal HM and Pathak A (2007) ${ }^{15}$ who studied a total of 300 cases and found M: F ratio was 1:2.7. Buchade D et al $(2011)^{4}$ also observed preponderance of female over male with a M:F ratio of 1:1.69. Harish D et al (2013) ${ }^{10}$ in their retrospective study comprising a total of 2042 medico-legal autopsies in which deaths due to burns comprised 381 (19\%) cases observed male: female ratio of 1: 1.7. Khandare SV and Pawale DA (2014) ${ }^{14}$ carried out a retrospective study of 1500 autopsies out of which
120 were deaths due to burns. Female preponderance was observed, with $77.5 \%$ and $22.5 \%$ deaths due to burns in females and males respectively.

Females were more prone to the burn injuries because of their domestic activities which require association with fire sources. Moreover, Indian women wear dresses like the sari and the salwar-kurta with dupatta, which are often made of synthetic material, covering almost the whole body. Such clothes make them prone to burn injuries.

This is contradictory to the study by Memchoubi and H. Nabachandra $(2007){ }^{17}$ who observed slight male 
preponderance, $50.76 \%$ and $49.23 \%$ in males and females respectively.

\section{Age wise distribution of cases}

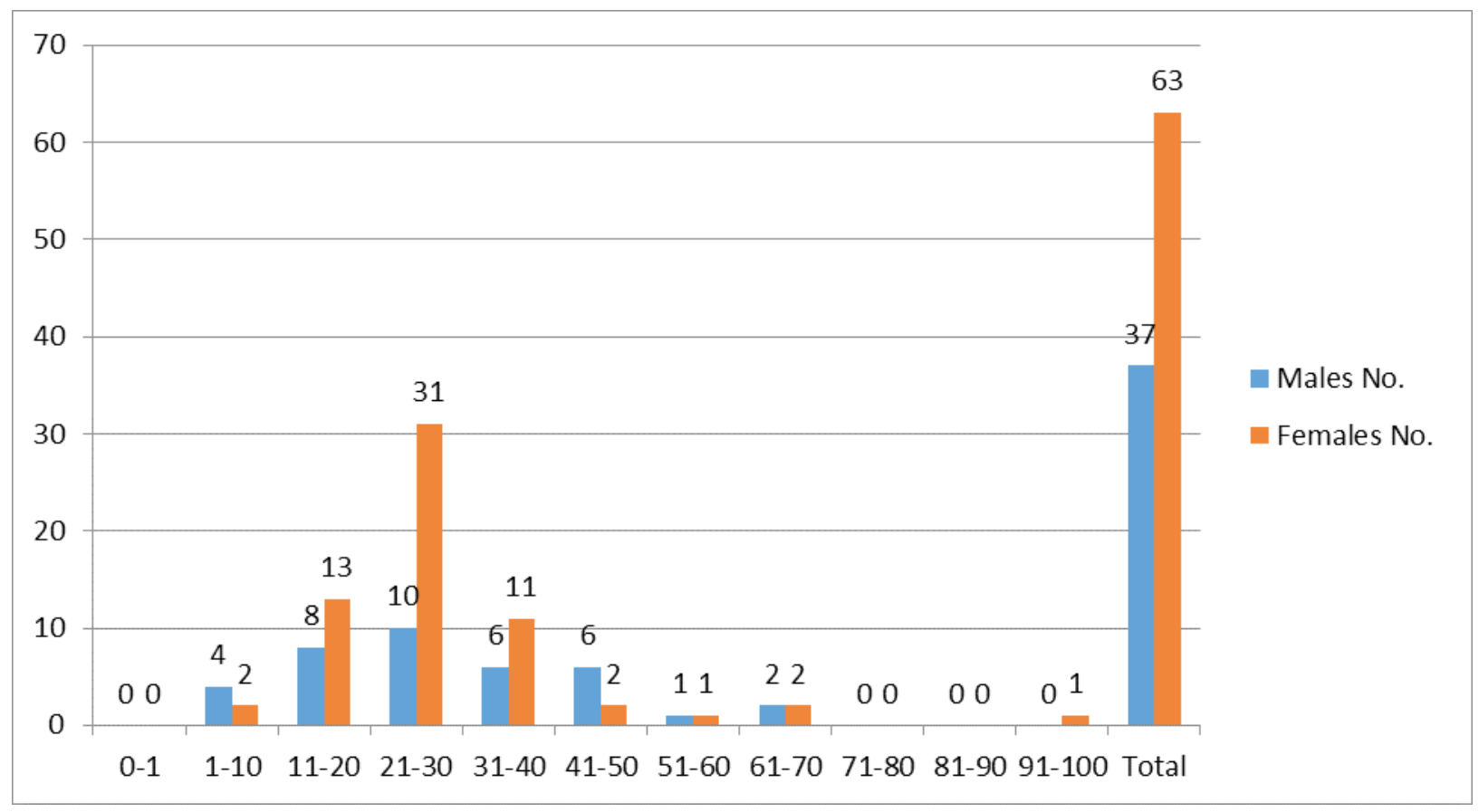

Graph -1: Age and Sex wise distribution of burn deaths $(\mathrm{n}=100)$

During the study period, maximum incidence was noted in females (31.00\%) as well as males (10.00\%) in the age group of 21-30 years. Similar findings have been reported by Harish D et al ${ }^{18}$, Memchoubi and H. Nabachandra $(2007)^{17}$, Mazumder A and Patowary A $(2013)^{16}$, Chawla R et al $(2011)^{5}$ and Ande JD et al (2013)2 . The age group 21-30 years is the young adult group and is the most common age for marriage. High incidence may be explained by the fact that young adults are generally active and exposed to hazardous situations both at home and at work.

\section{Distribution of cases according to Marital status}

Table-2: Distribution of burns in relation to sex and marital status

\begin{tabular}{|c|c|c|c|}
\hline Marital Status & $\begin{array}{c}\text { Male } \\
\text { No. }\end{array}$ & $\begin{array}{c}\text { Female } \\
\text { No. }\end{array}$ & $\begin{array}{c}\text { Total } \\
\text { No. (\%) }\end{array}$ \\
\hline Married & 23 & 51 & $74(74 \%)$ \\
\hline Unmarried & 13 & 11 & $24(24 \%)$ \\
\hline Widow & 0 & 1 & $1(1.00 \%)$ \\
\hline Widower & 1 & 0 & $1(1.00 \%)$ \\
\hline Total & 37 & 63 & $100(100 \%)$ \\
\hline
\end{tabular}


Most of the victims i.e. 74(74\%) were married and 24 (24.00\%) were unmarried with married-unmarried ratio of $3.08: 1$. Out of the females, $51(81 \%)$ were married and $11(17.40 \%)$ were unmarried, in contrast to males where 23 (62\%) were married and 13 (35\%) were unmarried. 1 (1.5\%) case was widow and 1 (2.7\%) case was widower Harish D et al $(2013)^{10}$, GowriS et al $(2012)^{7}$, Buchade D et al (2011) ${ }^{4}$, Mangal HM and Pathak A (2007) ${ }^{15}$ and Gaffar UB et al $(2008)^{6}$ also reported that maximum incidence was among married female in their early years of marriage, this is because of the marital maladjustment and bride burning for the want of dowry in recently married females.

\section{Distribution of cases based on Locality}

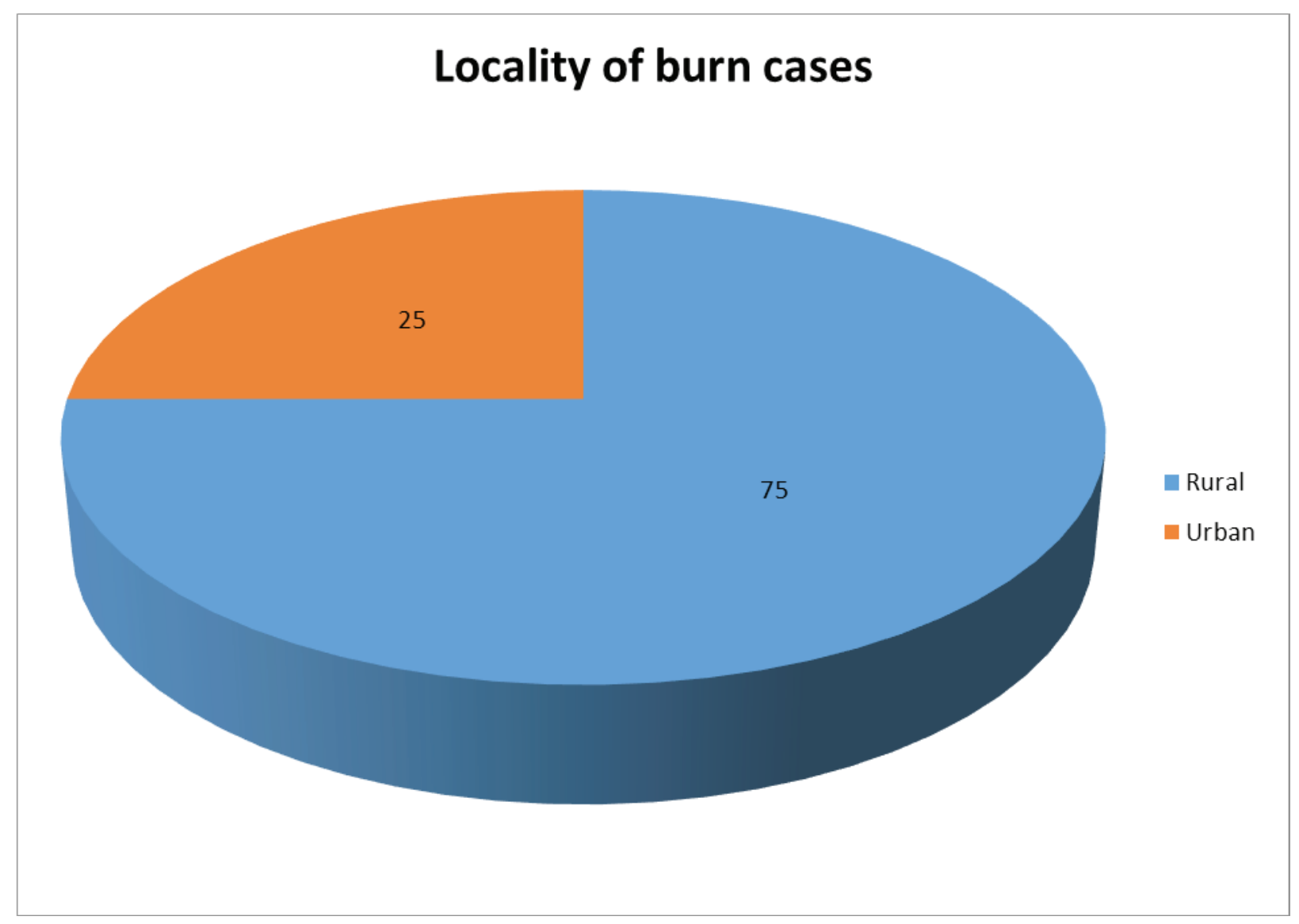

\section{Graph-2 depicts Locality wise distribution of burn cases}

Majority of the victims i.e. 75 (75.00\%) belonged to rural (village) areas and rest 25 (25.00\%) were from urban (city) areas. Gandhi Medical College and Hamidia hospital, Bhopal is a tertiary health care institute surrounded by villages on 3 sides. Burn victims due to serious nature of illness and because of medicolegal reasons have been referred to this apex hospital. Gaffar UB et al $(2008)^{6}$ in their study also noted that maximum number of victims were from rural areas $(68.4 \%)$ and less number of cases from urban areas $(31.6 \%)$. 


\section{Occupation wise distribution of cases}

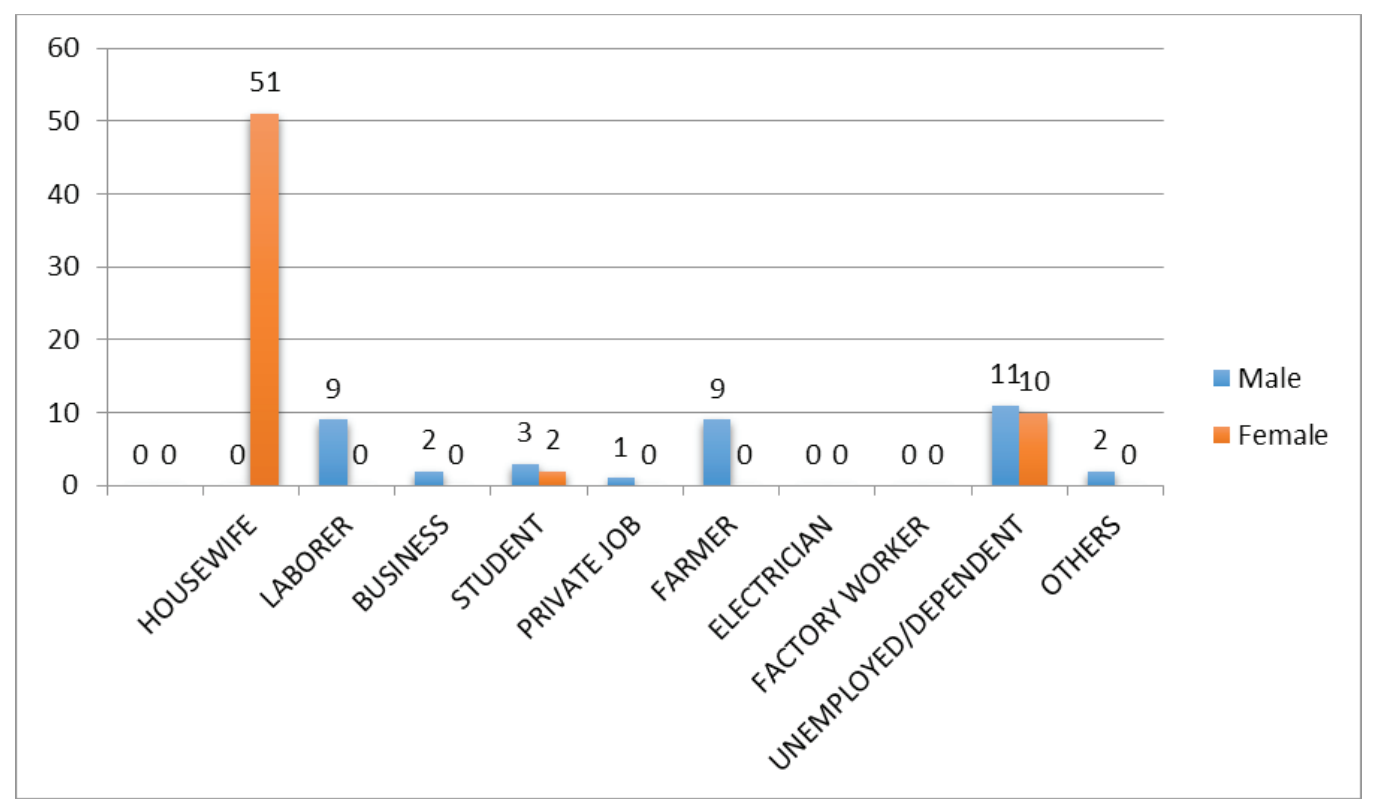

Graph-3: depicts Occupation wise distribution of burn cases

$51(81 \%)$ cases who suffered burn injuries were housewives followed by $2(3.00 \%)$ females who were students and $10(16.00 \%)$ were dependent/unemployed. In males, maximum cases reported were dependent/ unemployed, accounting to be $11(30.00 \%)$ followed by 9 (24\%) who were farmers and laborers 9 (24\%). Similarly, Aggarwal BBL and Chandra J (1970) ${ }^{1}$ observed that all the females of 3rd decade and some of 2nd decade who suffered burn injurieswere housewives.
Haralkar SJ and Rayate M (2005) ${ }^{9}$ also observed in their study of 343 admitted burn cases that $49.85 \%$ were housewives, $6.2 \%$ agri-labourers, $10.2 \%$ non agrilabourers, 3.5\% own business and unemployed $11.08 \%$ and doing no work were $18.06 \%$. Female preponderance is due to involvement of females in the kitchen work. Similar observation were made by Harish $\mathrm{D}$ et al $(2013)^{10}$ and Chawla R et al $(2011)^{5}$.

\section{Distribution of cases according to Socio-Economic status}

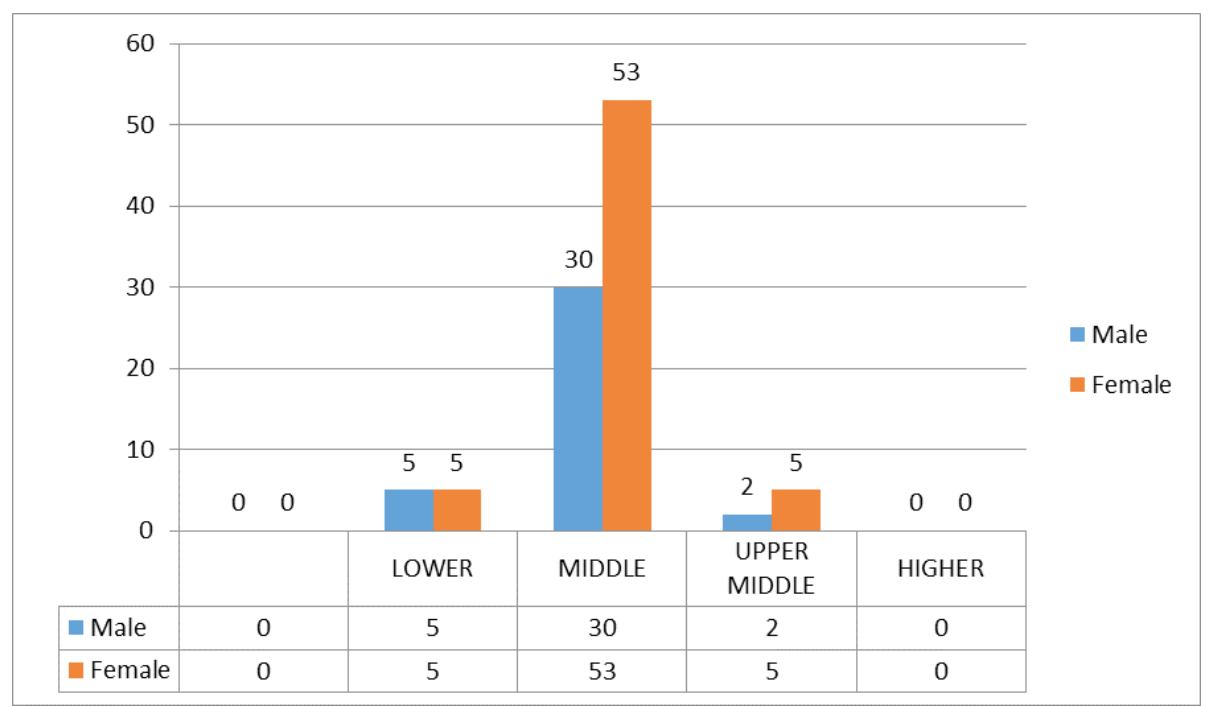

Graph-4: depicts distribution of burn cases according to socio economic status 
According to Kuppuswamy's classification of socio economic status, this study showed maximum number of burn cases belonging to middle class i.e. 83 (83\%) cases, with 53 (53\%) females. Minimum cases were in upper middle class i.e. 7 out of which 5 were females.

\section{Distribution of cases based on Source of Catching Fire}

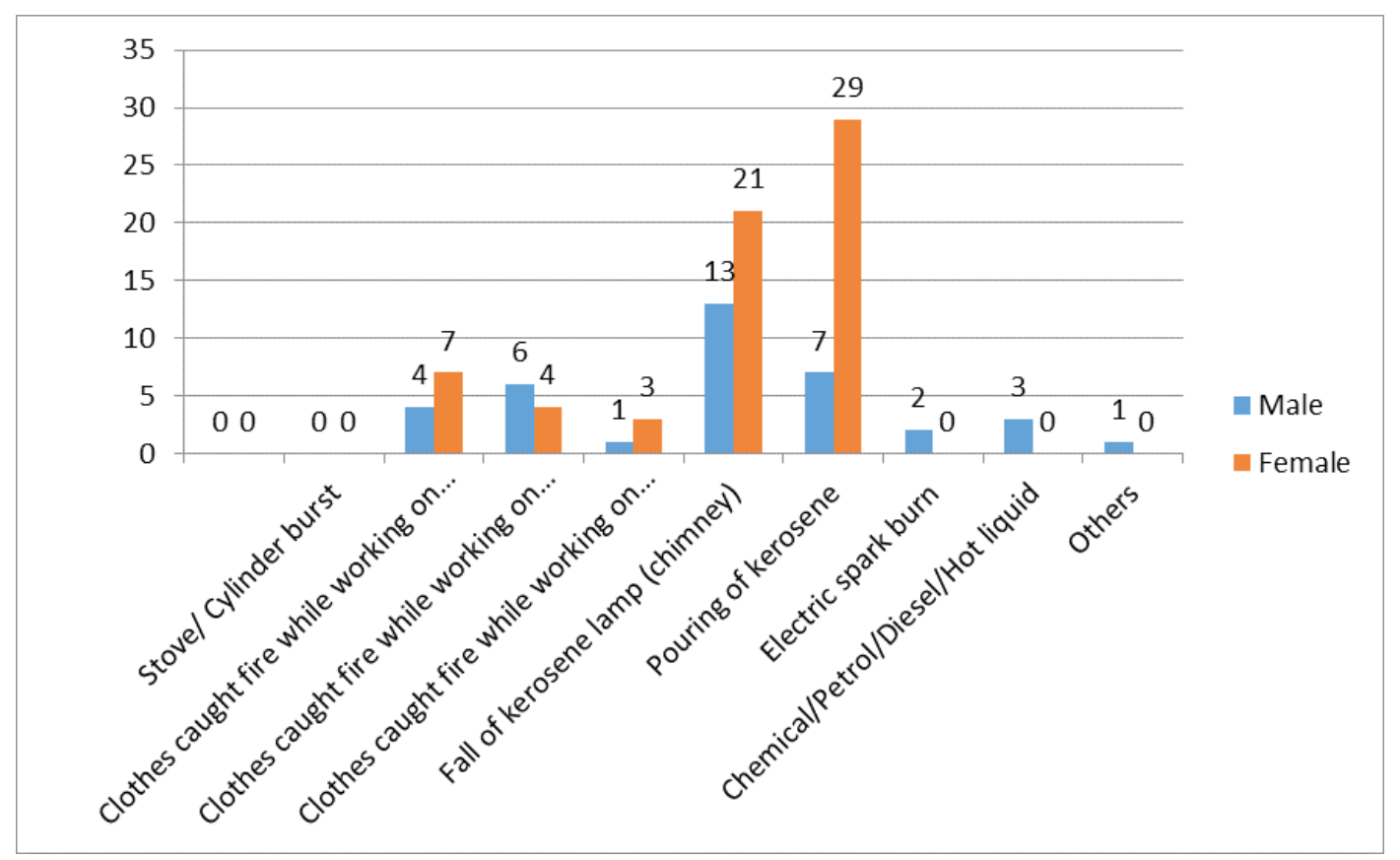

Graph-5: depicts distribution of burn cases according to Source of Catching Fire

The source of fire was kerosene (lamp (chimney)/ kerosene stove/ pouring of kerosene) in 79 (79.00\%) cases, being the commonest one; while gas (stove/ cylinder) was involved in $12(10 \%)$ cases and anghiti/ chullha in $8(6.67 \%)$. Overall, the universal source of fire in the household for cooking purposes were responsible for $94(94.00 \%)$ instances of the victims catching fire. Kerosene lamp (chimney) is very widely used in rural areas for lighting purpose. In most of the cases, mishandling of chimney results in it falling over body and catching fire, as observed in most of the cases. Fire due to electricity was responsible for $02(02.00 \%)$.

The observations of this study is in agreement with studies of Jayaraman V et al $(1993)^{12}$, Singh D et al $(2003)^{20}$, Bilwani PK and Gupta R $(2003)^{3}$ and Gupta $\mathrm{R}$ et al (2012) ${ }^{8}$. This was probably because kerosene is cheap and easily accessible and it was mostly included in the household or kitchen materials. Similar facts had been previously emphasized in studies by Ho WS et al $(2002)^{11}$ and Jaiswal AK et al $(2007)^{13}$.

\section{Conclusion}

It could be concluded from the present study that burn deaths have been found to be much more prevalent in females as compared to males, most of which were housewives, in young adults of age 21- 30 years, with preponderance in married population, mostly residing in rural areas with maximum number of burn cases seen in middle class, kerosene lamp being the most common source of catching fire.

This is similar to the findings of Mangal HM and Pathak A (2007) ${ }^{15}$,Buchade D et al(2011) ${ }^{4}$, Harish D et $\operatorname{al}(2013)^{10}$, Memchoubi and H. Nabachandra(2007) ${ }^{17}$, Mazumder A and Patowary A(2013) ${ }^{16}$, Ande JD et $\mathrm{al}(2013)^{2}$ and Aggarwal BBL and Chandra J(1970) ${ }^{1}$. Observations made by Jayaraman V et al (1993) ${ }^{12}$, Singh D et al $(2003)^{20}$, Bilwani PK and Gupta R(2003) ${ }^{3}$ and Gupta $\mathrm{R}$ et $\mathrm{al}(2012)^{8}$ also supports the findings of present study. 
As the problem of thermal deaths still persist in our country, the government along with various working groups and the NGOs, including the doctors need to put in more sincere efforts. Dowry deaths, curse to our so-called modern society, are still prevalent, in spite of stringent laws and amendments in the acts. Strict implementation of the Anti-dowry Act would go a long way in bringing down the incidence of these so called 'accidents'.

Following the safety instructions like putting the lights off while going out, wearing fitted and cotton cloths while cooking, not leaving a fire source unattended etc. will definitely help to reduce the incidence of burn injuries. The NGOs and social groups must arrange a periodic effort in educating the rural people. Steps should be taken not only to minimize burn mortality but also to prevent and reduce their incidence at least in cases where human errors and human greed plays a significant role.

\section{Conflict of Interest : None}

Source of Funding: self with assistance from the institute.

Ethical Clearance: The study protocol was approved by the Institutional Ethics Committee of Gandhi Medical College, Bhopal.

\section{References}

1. Aggarwal BBL, Chandra J. A Study of Fatal Cases of Burns in South Zone Delhi. Punjab Med J 1970; 20(12): 451.

2. Ande JD, Kumar SV, Satyadev M, Tirumala N, Guguloth K, Chandana N. Pattern of Thermal Burn Injuries and their outcomes at Burn Care Unit of Tertiary Hospital, Warangal, Andhra Pradesh, India. International Journal of Pharmaceutical Sciences Letters 2013; Vol. 3 (6): 288-295.

3. Bilwani PK, Gupta R. Epidemiological profile of burn patients in LG Hospital, Ahmedabad. Indian J Burns, 11, 2003; 63(4): 26,27.

4. Buchade D, Kukde H, Savardekar R. Pattern of Burn Cases Brought to Morgue, Sion Hospital, Mumbai: A Two Year Study. J Indian Acad Forensic Med 2011; 33(4): 311-312.
5. ChawlaRahul, Chanana Ashok, RaiHukumat. Clinico pathological profile in deaths due to burns. Journal of Indian Academy of Forensic Medicine. Jan-March 2011; Vol.33(1).

6. Gaffar UB, Husain M, Rizvi SJ: Thermal Burn: An Epidemiological Prospective Study. J Indian Acad Forensic Med 2008; 30(1): 10-14.

7. Gowri S, Vijaya N, Powar R, Honnungar R, Mallapur M D. Epidemiology and Outcome of Burn Injuries. J Indian Acad Forensic Med 2012; 34(4): 312-314.

8. Gupta R, Kumar V, Tripathi SK. Profile of the Fatal Burn Deaths from the Varanasi Region, India. Journal of Clinical and Diagnostic Research, 2012 May (Suppl-2); Vol- 6(4): 608-611.

9. Haralkar SJ, Rayate M. Socio-demographic profile of burn cases in the reproductive age group (1545 years) admitted in SCSM General Hospital, Solapur. Solapur Med J 2005; 2(2): 3-9.

10. Harish D, Kaur C, Singh A, Kumar A. A Comprehensive Analysis of Deaths due to Burns in a Tertiary Care Centre. J Punjab Acad Forensic Med Toxicol 2013; 13(2): 68-73.

11. Ho WS ,Ying SY, Burd A. Outcome analysis of 286 severely burned patients: Retrospective study. Hong Kong Med J 2002; 8 (4): 14.

12. Jayaraman V, Ramakrishnan MK, Davies MR. Burns in Madras, India: An analysis of 1368 patients in one year. Burns, 19, 1993, 339-44.

13. Jaiswal AK, Aggarwal H, Solanki P, Lubana PS, Mathur RK, Odiya S. Epidemiological and sociocultural study of burn patients in M.Y.Hospital, Indore. Indian J Plastic Surg 2007; 40: 158-63.

14. Khandare SV, PawaleDA.Study of Deaths due to Burns in Kolhapur Region.Journal of Forensic Medicine, Science and Law 2014; 23(2).

15. Mangal HM, Pathak A, Rathod JS. The Fire is Both "A Blessing \& Scourge to the Mankind". JIAFM 2007; 29(4): 75-77.

16. Mazumdar A, Patowary A. A Study of Pattern of Burn Injury Cases. J Indian Acad Forensic Med 2013; 35(1): 44-46.

17. Memchoubi, H. Nabachandra. A Study of Burn Deaths in Imphal. JIAFM 2007; 29(4): 131-134.

18. Modi NJ. Injuries from burns, lightning and electricity,Asphyxiants.Modi's Textbook of Medical Jurisprudence and Toxicology.20 $0^{\text {th }}$ Ed. 
Bombay; NMTripathi. 1983: page 182, 762.

19. World Health Organization. Burns.(online article) 2002.

20. Singh D, Dewan I, Pandey AN, Tyagi S. Spectrum of unnatural fatalities in the Chandigarh zone of northwest India - a 25 year autopsy study from a tertiary care hospital. Journal of Clinical Forensic Medicine2003; 10(3): 145 - 152. 